\title{
Use of text stimuli normalizes reality monitoring in schizophrenics
}

\author{
ROBBI R. TANENBAUM and PHILIP D. HARVEY \\ State University of New York at Binghamton, Binghamton, New York
}

\begin{abstract}
Reality monitoring performance was assessed in normal, manic, and schizophrenic subjects, with self-generated text as the stimuli. The subjects were asked to mentally plan or orally generate stories and then to identify the origin of the information that they had planned or generated. The subjects were also exposed to irrelevant, distracting story material while performing the task. The performance of all subjects was appreciably better than performance in other studies in which word-list reality monitoring was used, and distraction had no deleterious effect on performance. These results are discussed in terms of their implications for intentional versus unintentional encoding processes in schizophrenics.
\end{abstract}

Reality monitoring (Johnson \& Raye, 1981) is the process of attribution of the origin of information in memory to an internal or external source. In several studies of reality monitoring, Johnson and her colleagues have identified a number of characteristics of reality monitoring in normal individuals. For example, normal individuals manifest certain typical decision biases (Raye \& Johnson, 1980), in that, when they make attribution errors, they tend to report that they have only thought information that they have actually said. Furthermore, reality-monitoring discrimination ability appears to develop over time (Foley, Johnson, \& Raye, 1983), although decision error biases appear to be relatively stable across the developmental span.

Several theorists (e.g., Maher, 1983; Rochester, 1979) have asserted that communication disturbances in schizophrenia may be caused by failures of aspects of information-processing competence similar to those subsumed by the process of reality monitoring. In earlier studies of reality-monitoring ability in psychotic patients, Harvey (1985; Harvey, Earle-Boyer, \& Levinson, 1988) found that schizophrenic patients had characteristic problems in reality monitoring. Schizophrenic patients who manifested verbal communication disturbances (i.e., " formal thought disorder"') were less competent than normals at discriminating the actual origin of information that they had said, as opposed to thought, and tended to make recognition errors that were the polar opposite of normal biases. Harvey et al. (1988) found that the concurrent presence of reality-monitoring discrimination problems and a "think-report-say" recognition error bias predicted the

This research was supported by Grant MH38431 from the National Institute of Mental Health. The authors would like to thank the patients and staff at Binghamton Psychiatric Center for their assistance. Address reprint requests to Philip D. Harvey, Department of Psychiatry, Mt. Sinai Medical School, One Gustave L. Levy Place, New York, NY 10029. severity of communication disturbances much better than either problem alone.

In this report we present data from a modification of the reality-monitoring procedure as applied to schizophrenic and normal subjects and a psychiatric control sample. We changed the typical reality-monitoring task, in which the subject is asked to discriminate the origin of word stimuli from a list, by having the subjects discriminate the origin of word stimuli that had been contained in a story that they had either planned or planned and generated. We also had the subjects perform realitymonitoring operations while being exposed to irrelevant information, in order to manipulate overall demand on information-processing capacity. Schizophrenics typically manifest a relatively robust performance decrement when asked to perform information-processing operations, particularly those involving encoding, in the presence of distracting information. We wanted to see if this effect extended to the processes involved in reality monitoring as well.

\section{METHOD}

\section{Subjects}

Psychiatric patients (21 schizophrenics and 16 manics) who were consecutive admissions to the acute treatment unit at Binghamton Psychiatric Center served as subjects for this study. Diagnostic information was collected by trained interviewers (graduate students) using the Schedule for Affective Disorders and Schizophrenia (SADS; Spitzer, Endicott, \& Robins, 1978), and all diagnoses utilized DSM-III criteria (American Psychiatric Association, 1980). Patients with diagnoses of alcoholism or disorders of the central nervous system were not approached. All patients were receiving medication at the time of the study, and information on type and amount of medication was recorded. The diagnostic interview was tape recorded for assessment of diagnostic reliability and for completion of thought-disorder ratings. The subjects were tested approximately 3 days after their initial clinical assessments.

A normal control group $(n=15)$ was selected from the community in the Binghamton area. Subjects with a personal or familial history of psychiatric hospitalization or treatment were not included in this sample. The three groups of subjects did not differ significantly in age or 
years of education, and the two patient samples were similar in their numbers of prior hospitalizations.

\section{Task, Materials, and Procedure}

Before testing, the subjects were told that the experimenter was interested in their ability both to make up stories and to recognize the origin of the information afterward. The experimenters (undergraduate assistants) made certain that the subjects fully understood the instructions, with one practice trial administered before testing began.

The subjects were presented with eight pairs of eight-word lists and were asked to prepare a story using all the words in each list. Following Waters and Lomenick (1983), each word list consisted of eight thematically related words, generated intuitively, with the words associated with a listed topic. For example, under the topic heading exercise, the words jogging, bicycle, gym, pool, class, instructor, sneakers, and sweatshirt were presented. For each of the eight pairs, the subjects were required to generate one story aloud ("say" condition) from one word list and to mentally plan another story ("think" condition) from the other word list. For both conditions, the subjects were instructed to use all of the words in the order in which they were written on the cards. In both say and think story conditions, the subjects were exposed to irrevelant distracting information on half of the trials during planning or generation in a $2 \times 2 \times 2$ (plan/generate $\times$ distraction/nondistraction $\times$ order [plan first, generate first]) design. In distraction conditions, the subjects were exposed to a tape recording, played over headphones, of an unrelated story being read in a man's voice, and were instructed to ignore this distraction information. The presentation of all conditions was randomly ordered across the subjects; the 16 word lists were assigned randomly to conditions and remained fixed throughout the experiment. For each of the eight pairs of lists, a recognition sheet was developed that contained the 16 word-list words and 8 recognition foils. The recognition foils were unrelated to each other or to the topics associated with the word-list words. After the completion of each trial, the subjects were presented with the appropriate recognition sheet and were asked to make a choice recognition of the say words, think words, and recognition foils, with instructions to guess if they were unsure of the origin of the information.

\section{Clinical Thought-Disorder Ratings}

Clinical thought-disorder ratings were generated by two trained raters using the Scale for the Assessment of Thought, Language and Communication (Andreasen, 1979). The ratings were based on the tape-recorded clinical interview (SADS) and the two raters, who were blind to diagnostic status, generated the ratings. Ratings for the present study were a subset of a much larger sample of subjects who had also been rated. Interrater reliability (kappa) for the total sample of ratings averaged .90 . Five-point ( 0 to 4 ) ratings were generated for two negative symptoms (poverty of speech and poverty of content of speech) and five positive symptoms (pressure of speech, illogicality, tangentiality, derailment, and incoherence). Aggregate ratings for the two types of thought-disorder ratings, obtained by summing the individual ratings, are presented in Table 1.

\section{RESULTS}

\section{Between-Groups Differences}

The dependent variables for the study were discrimination ratios, reality-monitoring errors (think-report-say and say-report-think), and false recognitions (new-reportsay and new-report-think). Following Foley et al. (1983), the discrimination ratios were computed by summing the total of correctly recognized words from each condition and dividing that number by all words recognized as old (i.e., reality-monitoring errors and all correct recognitions). This measure provides an index of accuracy across conditions, and ranges from 0 to 1.0 . We first examined whether the order in which stories were planned and generated had any significant effect on recognition per-
Table 1

Means and Standard Deviations for Thought Disorder and Reality Monitoring

\begin{tabular}{|c|c|c|c|c|c|c|}
\hline \multirow[b]{3}{*}{ Condition } & \multicolumn{6}{|c|}{ Group } \\
\hline & \multicolumn{2}{|c|}{$\begin{array}{l}\text { Schizophrenic } \\
\quad(n=21) \\
\end{array}$} & \multicolumn{2}{|c|}{$\begin{array}{c}\text { Manic } \\
(n=16)\end{array}$} & \multicolumn{2}{|c|}{$\begin{array}{l}\text { Normal } \\
(n=15)\end{array}$} \\
\hline & $M$ & $S D$ & $M$ & $S D$ & $M$ & $S D$ \\
\hline \multicolumn{7}{|c|}{ Positive Thought Disorder } \\
\hline & 1.81 & 2.50 & 4.19 & 2.97 & & \\
\hline \multicolumn{7}{|c|}{ Negative Thought Disorder } \\
\hline & 1.48 & 2.04 & .87 & 1.15 & & \\
\hline \multicolumn{7}{|c|}{ Discrimination Ratio } \\
\hline NP-NG & .85 & .17 & .88 & .17 & .99 & .00 \\
\hline DP-NG & .89 & .14 & .88 & .17 & .99 & .02 \\
\hline NP-DG & .89 & .16 & .79 & .18 & .98 & .02 \\
\hline DP-DG & .85 & .14 & .83 & .16 & .98 & .03 \\
\hline \multicolumn{7}{|c|}{ Think-Report-Say Errors } \\
\hline NP-NG & .83 & 1.15 & .75 & .95 & .03 & .13 \\
\hline DP-NG & .61 & .89 & .87 & 1.30 & .00 & .00 \\
\hline NP-DG & .61 & 1.20 & 1.65 & 1.76 & .23 & .32 \\
\hline DP-DG & .97 & 1.24 & .87 & .95 & .03 & .13 \\
\hline \multicolumn{7}{|c|}{ Say-Report-Think Errors } \\
\hline NP-NG & .83 & 1.66 & .56 & 1.04 & .00 & .00 \\
\hline DP-NG & .69 & 1.18 & .43 & .77 & .13 & .30 \\
\hline NP-DG & .78 & 1.63 & .75 & .79 & .03 & .13 \\
\hline DP-DG & .85 & 1.62 & .81 & .99 & .10 & .28 \\
\hline \multicolumn{7}{|c|}{ New-Report-Say Errors } \\
\hline NP-NG & .33 & .66 & .31 & .70 & .33 & .49 \\
\hline DP-NG & .19 & .33 & .06 & .17 & .06 & .17 \\
\hline NP-DG & .14 & .39 & .46 & .53 & .10 & .28 \\
\hline DP-DG & .09 & .25 & .21 & .51 & .00 & .00 \\
\hline \multicolumn{7}{|c|}{ New-Report-Think Errors } \\
\hline NP-NG & .59 & 1.46 & .43 & .94 & .06 & .26 \\
\hline DP-NG & .40 & 1.35 & .31 & .87 & .03 & .13 \\
\hline NP-DG & .40 & 1.32 & .21 & .51 & .13 & .30 \\
\hline DP-DG & .50 & 1.47 & .34 & .81 & .16 & .30 \\
\hline
\end{tabular}

Note $-\mathrm{N}=$ nondistraction, $\mathrm{D}=$ distraction, $\mathrm{P}=$ plan, $\mathrm{G}=$ generate.

formance. An analysis of variance examining order and order $\times$ diagnosis interactions for all variables revealed no main effects or interactions. We then averaged across order, and the resulting means and standard deviations for performance are presented in Table 1.

Separate diagnosis (manic, schizophrenic, normal) $\times$ condition (distraction, nondistraction) $\times$ source (planned, generated) repeated measures analyses of variance were computed across each of the dependent variables. There was a significant main effect of diagnosis for discrimination ratios $[F(2,49)=6.60, M S e=.35, p<.05]$. Newman-Keuls tests reveaied that normal subjects had the highest discrimination ratios in all conditions, with no other differences significant. A diagnosis $\times$ condition $\times$ source triple interaction was found for think-reportsay errors $[F(2,49)=3.01, M S e=2.49, p<.05]$. Newman-Keuls tests were calculated to follow up this interaction. Normals had the fewest think-report-say errors in all conditions, with no significant internal differences 
across conditions. Manic subjects had more errors in the NP-DG condition than schizophrenics, who did not differ from the normals. Schizophrenics manifested no internal differences across conditions. No effects were significant for say-report-think errors.

A main effect of condition was found for new-reportsay errors $[F(1,49)=12.92, M S e=1.58, p<.05]$, with all subjects making more errors when not distracted. For new-report-think errors, a condition $\times$ source double interaction was found $[F(1,49)=5.23, M S e=.51$, $p<.05$ ]. Newman-Keuls tests revealed that all groups made significantly more new-report-think errors in the NP-NG condition than in the other conditions.

\section{Correlational Analysis}

All discrimination and error scores were correlated with thought-disorder ratings separately for the manic and schizophrenic samples. For both samples, fewer correlations between thought-disorder scores and realitymonitoring performance were significant than would be expected by chance.

\section{DISCUSSION}

Reality-monitoring operations performed on text stimuli led to high accuracy levels for both schizophrenics and normal subjects. In earlier studies (Harvey, 1985; Harvey et al., 1988), the say-think discrimination ratios for normals for immediate choice recognition of eight-word lists ranged from .72 to .79 , with patients' performance ranging from .61 to .79. The performance of the patients in the present study, therefore, was substantially better than the performance of normals in Harvey's earlier word-list studies; consequently, the number of recognition errors was reduced by about $50 \%$ compared with the earlier studies. The presence of distracting information had an inconsequential effect on recognition performance and errors for all subjects. Clearly, generation of text led to substantially enhanced recognition performance.

One possible explanation for the high levels of performance in the present study is that subjects recalled the topics of the stories that they planned or generated and then used this information to scan the recognition sheets. It is unlikely, however, that the schizophrenics adopted this strategy. It has been found that schizophrenics fail to adopt encoding strategies even when provided with a strategy and instructed to use it (Koh, Kayton, \& Berry, 1973), although if encoding is incidentally introduced (through various "classification" tasks), memory performance approaches that of normals (Koh, Kayton, \& Peterson, 1976). Similarly, Harvey, Earle-Boyer, Wielgus, and Levinson (1986) found that when schizophrenics generated text passages their memory was appreciably better than when they listened to highly organized text. Therefore, both the present study and earlier studies have suggested that intentional application of encoding strategies is impaired in schizophrenics, but that when encoding is unintentionally induced, schizophrenics' performance is normalized. It also appears that distraction does not impair schizophrenics when they are performing tasks that do not require them to intentionally use encoding strategies. In earlier studies, in which distraction had a deleterious effect on information processing (e.g., Harvey et al., 1988; Oltmanns, 1978; Oltmanns \& Neale, 1975), no manipulations were conducted to induce unintentional encoding.

In earlier reality-monitoring studies with schizophrenics (Harvey, 1985; Harvey et al., 1988), word-list stimuli led to poorer discrimination per- formance than that of the present study, and the discrimination failures were strongly associated with thought disorder. It is possible that the task used in the present study was a more naturalistic analogue of the actual speech production and generation process than is word-list reality monitoring. The present findings suggest that the earlier findings were task specific and are not generally applicable to all discourse operations situations requiring reality monitoring. In line with this notion, Harvey et al. (1988) found in a longitudinal design that reality-monitoring deficits manifested a consequential and nonantecedent relationship with thought disorder. The findings of both Harvey et al.'s study and the present study suggest a complicated relationship between realitymonitoring operations and discourse failures in schizophrenia.

\section{REFERENCES}

American Psychiatric Association. (1980). Diagnostic and statistical manual of mental disorders (3rd ed.). Washington, DC: Author.

ANDREASEN, N. C. (1979). Thought, language and communication disorders: II. Diagnostic significance. Archives of General Psychiatry, 30, 1325-1330.

Foley, M. A., Johnson, M. K., \& Raye, C. (1983). Age related changes in confusion between memories for thoughts and memories for speech. Child Development, 54, 51-60.

HaRVEY, P. D. (1985). Reality monitoring in mania and schizophrenia: The association between thought disorder and performance. Journal of Nervous and Mental Disease, 173, 67-73.

Harvey, P. D., Earle-Boyer, E. A., \& Levinson, J. C. (1988). Cognitive deficits and thought disorder: A retest study. Schizophrenia Bulletin, 14, 57-66.

Harvey, P. D., Earle-Boyer, E. A., Wielgus, M. S., \& Levinson, J. C. (1986). Encoding, memory and thought disorder in schizophrenia and mania. Schizophrenia Bulletin, 12, 252-261.

Johnson, M. K., \& RAYE, C. L. (1981). Reality monitoring. Psychology Review, 88, 67-85.

KoH, S. D., Kayton, L., \& BerRy, R. (1973). Mnemonic organization in young nonpsychotic schizophrenics. Journal of Abnormal Psychology, 81, 299-310.

Koh, S. D., Kayton, L., \& Peterson, R. (1976). Affective encoding and consequent remembering in schizophrenic young adults. Journal of Abnormal Psychology, 85, 156-166.

Maher, B. A. (1983). A tentative model of schizophrenic utterance. In B. A. Maher (Ed.), Progress in experimental personality research (Vol. 12, pp. 2-52). New York: Academic Press.

OltmanNs, T. F. (1978). Selective attention in schizophrenic and manic psychoses: The effect of distraction on information processing. Journal of Abnormal Psychology, 87, 212-225.

Oltmanns, T. F., \& Neale, J. M. (1975). Schizophrenic performance when distractors are present: Attentional deficits or differential task difficulty? Journal of Abnormal Psychology, 84, 205-209.

RAYE, C. L., \& JoHNSON, M. K. (1980). Reality monitoring vs. discrimination of two external sources. Bulletin of the Psychonomic Society, 15, 405-408.

ROCHESTER, S. R. (1979). Are language disorders in acute schizophrenia actually information processing problems? Journal of Psychiatric Research, 14, 275-283.

SPITZER, R. L., EndicotT, J., \& RoBINs, L. (1978). The Schedule for the Affective Disorders and Schizophrenia. New York: Biometrics Research.

WATERS, H. S., \& Lomenick, T. (1983). Levels of organization in descriptive passages: Production, comprehension, and recall. Journal of Experimental Child Psychology, 35, 391-408.

(Manuscript received for publication December 5, 1987.) 